\title{
A Letra e O SIGNifiCANTE-NOME PRÓPRIO NA PSICOSE ${ }^{\star}$
}

\author{
Mariluci Novaes ${ }^{\star}$
}

\begin{abstract}
Resumo
O artigo visa traçar alguns parâmetros, presentes na lingüística e na lógica, decorrentes do lugar do nome próprio na língua e na cultura. Ao ser interpelado pelo Outro, o sujeito se defrontará com injunções imaginárias, simbólicas e do real que tornam esse nome único e cuja referência não é o ser, mas o desejo do Outro a partir do qual a nomeação se efetivou, numa forma de inserção na Lei da língua, da cultura e do desejo. Se o psicótico reage mal a seu nome é possível que ele não se reconheça nessas injunções montadas em torno de seu nome.
\end{abstract}

Palavras-chave: Letra. Significante-Nome Próprio. Psicose.

\section{THE LETTER AND THE PROPER-NAME SIGNIFIER IN PSYCHOSIS}

\begin{abstract}
The purpose of the article is to show some parameters formulated in linguistics and logic, by which the locus of proper names in language and culture is established. The sole reference of proper name is not the being, but the desire of the Other stated at the moment of the performative nomination. The act of nominating by a proper name conceives a set of Imaginary and Symbolic bonds, one way of admission on the Laws of language, culture and desire. Whether psychotics react badly to their names, it is possible that they do not recognize themselves in these injunctions around their names.
\end{abstract}

Keywords: Letter. Signifier-Proper Name. Psychose.

* Fonte de Financiamento: este artigo apresenta resultados finais encontrados na pesquisa Os nomes próprios nas psicoses como operadores imaginários de identidade, desenvolvida no período de março de 2003 a fevereiro de 2005, apoiada financeiramente pelo CNPq com bolsa de produtividade em pesquisa (Processo $n^{\circ} 303182 / 2002-4$ ) e com auxílio financeiro para aquisição de material, por meio do Edital 06/2003, para a área de Ciências Humanas (Processo no 402924/ 2003-7).

$\star \star$ Professora de lingüística do Departamento de Ciências da Linguagem, Universidade Federal Fluminense. Endereço residencial: Avenida Roberto Silveira, 409, apto. 1302, Icaraí, CEP 24230153, Niterói - RJ.

E-mail: mnovaes@vm.uff.br 


\section{INTRODUÇÃo}

Vou definir inicialmente nomes próprios como operadores lingüísticos que marcam nos enunciados as injunções ${ }^{1}$ imaginárias e simbólicas com as quais um sujeito da enunciação sempre se defronta ao ser chamado por seu nome. Tal definição deriva de uma releitura do que a lógica e a lingüística propõem a respeito do objeto de referência do nome próprio. Para isso, segui ainda as pistas deixadas por Lacan nas aulas dos dias 6, 13 e 20 de dezembro de 1961 e que constituíram o Seminário IX - A identificação [19--?] e nos textos A instância da letra no inconsciente ou a razão desde Freud e De uma questão preliminar a todo tratamento possível da psicose (LACAN, 1998).

Primeiramente, vou explorar as conseqüências que uma definição como esta pode ter na escuta da linguagem nas psicoses, deslocando algumas questões tradicionais propostas pela lingüística, a partir do que a lógica diz. Os deslocamentos iniciais já haviam sido efetivados por Lacan, o que se seguirá, portanto, é uma releitura dos pontos que me pareceram oportunos, tanto na lingüística quanto na lógica e na psicanálise. Em segundo lugar, vou propor outras questões para se situarem as noções de "letra" e de "significante-nome próprio" na teoria sobre as psicoses.

Os nomes próprios de pessoas, além de se distinguirem dos nomes comuns por suporem um objeto referente único, necessitam de um ato de nomeação específico, que, normalmente será autenticado na forma da Lei por meio das certidões de nascimento. É necessária uma circunstância de enunciação específica para que alguém atribua um nome a um bebê. Por esse ato, confirmado pela Lei, uma criança passa a fazer parte de uma família e de uma comunidade social. Ou seja, a sua existência humana depende de um ato performativo de seus pais ou de alguém responsável por ela.

Quando Austin (1962) sugeriu que alguns enunciados tinham a função de realizar uma ação, ele não estava se referindo explicitamente aos nomes atribuídos aos seres humanos (aliás, ele nem faz referência a isso). Seu exemplo clássico, "I name this ship the Queen Elizabeth" (as uttered when smashing the bottle against the stem)", descreve um conjunto de ações que tornam o batismo do navio um ato oficial: são necessários a enunciação - "Eu batizo este navio Rainha Elizabeth" e o ato de quebrar a garrafa no casco do navio. Levando às ultimas consequiências a proposta de Austin, pode-se dizer que, muitas vezes, os atos performativos de linguagem são ações jurídicas, como testamentos, casamentos, certidões em geral (por exemplo, alguém só é considerado legalmente morto, se houver uma certidão de óbito; em todos os rituais de passagem, há um documento escrito que autentica a passagem). Os atos performativos possuem força de lei, fazem parte de rituais de uma determinada cultura e são verdadeiros atestados de inscrição simbólica do sujeito.

Lyons introduziu o nome técnico "nomeação performativa"2 para identificar situações em que quando "X nomeia uma pessoa como 'João', entendemos 
que X atribui o nome ‘João' a essa pessoa” (LYONS, 1977, p. 179). Ou seja, não basta escolher um nome próprio, é preciso fazer um ato de atribuição:

O princípio de que os nomes próprios não têm sentido não é invalidado pelo fato de a nomeação performativa formal ou informal poder ser determinada por certas condições culturalmente prescritas de conveniência semântica. Em determinadas culturas, há um conjunto mais ou menos bem definido de nomes de pessoas institucionalizados (João, Maria etc.) que são atribuídos às crianças (LYONS, 1977, p. 181).

Lyons não desenvolve as consequiências decorrentes do ato de nomeação para o sujeito que se torna objeto desse ato, nem explicita o que quer dizer com "conveniência semântica", mas reconhece os vínculos que há entre esse ato e as instituições sociais. Não são atos arbitrários, mas atos que seguem uma certa lógica de inclusão do objeto nomeado no circuito da Lei: há uma distribuição de nomes distintos para meninos e meninas, para diferentes classes sociais, gerações, regiões, religiões etc. ${ }^{3}$

A falsa convicção de livre-arbítrio na atribuição de um nome para uma criança (alguns são possíveis e outros, interditados) indica uma ação performativa bem peculiar (na proposta original de Austin, o ato performativo é um ato de linguagem voluntário do enunciador). É de um lugar Outro (fantasmático para os pais que não são senhores de suas escolhas) que um nome surgirá, um nome que marcará "ao pé da letra" o destino do sujeito e suas futuras regras de endereçamento na linguagem. Toda vez que tiver de atender a uma interpelação ${ }^{4}$ por esse nome o sujeito se defrontará com as injunções imaginárias, simbólicas e do real que tornaram a escrita desse nome única e cuja referência imaginária é o ser, a partir do desejo do Outro por meio do qual a nomeação se efetivou. O sentido de interpelação é jurídico mesmo, pois marca "um ato jurídico, judicial ou extrajudicial, pelo qual é declarada ao devedor a exigência do cumprimento de uma obrigação civil, sob pena de incorrer em mora" (HOUAISS, 2001). O sujeito sempre está em débito.

Lacan refere-se aos lógicos e aos lingüistas para desenvolver algumas questões que estão subsumidas na relação entre significante, sujeito, identificação e nomes próprios. Remanejando a abordagem tradicional de que os nomes próprios servem aos processos de individuação de seres, colocará a dependência do sujeito na relação com o significante, mais especificamente com a letra. Com isso, a suposta relação de identidade entre nome próprio e seu titular, conforme proposta por Kripke (1982), vê-se direcionada para o real, já que o campo imaginário da identificação é da ordem do significante, do equívoco:

Se eu digo meu avô é meu avô vocês deverão de qualquer maneira compreender que aí não existe nenhuma tautologia: que meu avô, o primeiro termo é um uso de indicador do termo "meu avô", que não é sensivelmente diferente de seu nome próprio. [...] Se todo mundo, não apenas os lógicos, fala de "a" quando se trata de "a é a", não é mesmo assim por 
mero acaso. Porque para suportar isto que se deseja é preciso uma letra (LACAN, [19--?], p. 5-6).

A proposta lacaniana de marca distintiva para se dar conta do nome próprio parece enfatizar o seu funcionamento como aparição nos enunciados na forma de um enigma, uma letra que pode virar um significante que, por sua vez, pode virar "signo" pela inserção da função do sujeito (LACAN, [19--?], p. 40). É desse efeito significante do nome próprio que surge o lugar da função sujeito:

É exatamente aqui que aparece a função, o valor do significante como tal, na medida mesma da qual se trata este sujeito que nos interrogamos sobre a relação desta identificação do sujeito com isto que é uma dimensão diferente de tudo que é da ordem do aparecimento e do desaparecimento, a saber, o estatuto do significante (LACAN, [19--?], p. 3).

O sujeito, portanto, será chamado à decifração daquele significante, por outro significante (diga-se de passagem), em tudo aquilo que essa "marca entalhada" carrega de injunções do imaginário, do simbólico e do real e de todos os desdobramentos decorrentes desses três registros. Lacan apresenta uma definição para letra: "designamos por letra este suporte material que o discurso concreto toma emprestado da linguagem" e isso devido à "razão primeira de que a linguagem com sua estrutura preexiste à entrada de cada sujeito num momento de seu desenvolvimento mental" (LACAN, 1998, p. 498). Arrisco-me a fazer uma leitura dessa passagem de uma maneira tautológica: a letra é a letra, sabendo-se de antemão que a primeira menção diz respeito à letra na psicanálise e, a segunda, à letra como forma de inscrição da escrita alfabética. Assim como a escrita alfabética serve à linguagem comum, a letra serve à escrita do inconsciente. E qual seria a relação da letra com o significante-nome próprio?

\section{AS INJUNÇÕES IMAGINÁRIAS, SIMBÓLICAS E DO REAL NO SIGNIFICANTE-NOME PRÓPRIO}

Uma das particularidades dos nomes próprios é levar ao pé da letra o sistema fonético-fonológico de uma língua, apesar de pertencerem a uma classe de palavras que se encontra numa posição exterior ao sistema da língua. Nomes próprios não são signos para a lingüística. Apesar disso, na dimensão sonora e distintiva do nome próprio está lá presente a harmonia fonêmica de uma língua, aquela que permite que o nome seja pronunciado (por exemplo, o nome "Washington" pode até manter a escrita original, desde que a pronúncia sofra os constrangimentos lingüísticos de ser [óxiton] ou [uóxito] etc.). Uma outra interdição se faz presente: a tradução para uma outra língua, em virtude de o nome próprio ser a inscrição simbólica de uma pertença, no sentido de domínio, de um objeto privilegiado, qualquer coisa que, por disposição de lei ou destinação natural, encontra-se ligada ao uso de outra como acessório, apêndice ou complemento (HOUAISS, 2001).

Assim, a primeira injunção imaginária presente no nome próprio seria sua função primeira de referência a um objeto único. As outras classes de palavras da 
língua, como os substantivos, não realizam a referência imediata a um objeto. A intraduzibilidade do nome próprio, contudo, para Lacan, não se deve à identidade fonêmica de uma língua, mas sim à função mesma do nome de designar diretamente o objeto, por meio de uma escrita. Sendo da ordem da escrita ou sendo da ordem fonético-fonológica, nomes próprios não se prestam à tradução e o que impede isso, a meu ver, é a Lei de cada língua. Ao vincular-se a uma língua, o nome próprio carregaria em si a injunção imaginária da referência a um ser único e a injunção simbólica de estar inscrito na linguagem por meio de uma língua.

A lingüística ${ }^{5}$ trata os nomes próprios, normalmente, a partir do discurso da Lógica: ${ }^{6}$ nomes próprios são termos singulares por oposição aos nomes comuns, guardadas as devidas diferenças com as quais essa particularidade é desenvolvida teoricamente por cada autor:

Os nomes próprios, quando empregados como expressões referenciais, identificam os seus referentes, não os descrevendo em termos de uma propriedade relevante que o nome denota, mas utilizando a associação única e arbitrária entre um nome próprio e o seu portador (LYONS, 1977, p. 176).

Somente os nomes comuns, os substantivos, funcionariam como predicados de vários seres cujas referências podem se aplicar a mais de um objeto. Quando uso o termo "maçã" em "Maçã não engorda", denoto uma classe de objetos que possuem tais propriedades que são reconhecidas como aquelas de uma determinada fruta - a "maçã". Para fazer referência a uma única maçã, como em "A maçã está estragada", o enunciado teria de ser proferido numa situação de enunciação específica em que tanto o falante quanto o ouvinte reconhecessem que se tratava daquela única maçã que estava sobrando na geladeira.

Com os nomes próprios, tudo se passa como se a cada vez que se diz um nome sempre um mesmo portador a esse nome será referido e evocado. Resumidamente, poderíamos afirmar que são duas as funções características dos nomes próprios: a referencial e a vocativa. A função referencial pode decorrer de um ato de "chamar a atenção do interlocutor para a presença da pessoa que se nomeia ou para lembrar ao ouvinte a existência dessa pessoa" (LYONS, 1977, p. 178). A função vocativa decorre do ato de atrair a atenção da pessoa que está sendo chamada pelo nome. A "enunciação vocativa de um nome próprio" foi considerada por Granger (1982) como uma forma de interpelação virtual que só pode aparecer numa relação entre um enunciado e suas circunstâncias de enunciação. Ou seja, ao ouvir um nome, alguém se reconhecerá como referente desse nome.

Para Granger (1982), a função de interpelação virtual vem do fato de que o nome é livremente atribuído a um indivíduo em seu nascimento e esse designador rígido (no sentido formulado por Kripke, 1982) identifica aquele indivíduo independentemente dos predicados que possam ser atribuídos a ele. De um ato de nomeação primeiro, qualquer evocação dar-se-á na forma de interpelação desse nome. Para Kripke (1982), há uma relação entre nomeação e necessidade, que se 
apóia na tese da identidade, ou seja, na relação entre corpo e espírito, naquilo que é necessário ou contingente na identidade dos predicados de um nome próprio.

Espera-se que a atribuição de um nome de batismo, por meio de um ato de linguagem, deva ser transmitida de pessoa a pessoa fixando cada vez sua referência em todas as situações discursivas em que esse nome for convocado. A referência é reforçada pela repetição, desde a nomeação performativa, reproduzindo o efeito legal do nome que só pode ser desfeito juridicamente sob estritas condições. O nome de uma pessoa torna-se, então, uma parte essencial do sujeito. A re-nominação, quando ocorre, é também performativo-jurídica, por exemplo, quando uma mulher agrega o nome de família do marido registra um rito de passagem - um nome de solteira para um nome de casada.

A relação de identidade se estabelece pela repetição do nome, a partir do nascimento, de forma extensiva a todos os períodos de tempo de sua existência. Isso poderia pressupor que alguém existindo num tempo seria o mesmo ser em outro tempo ou, colocando de forma mais coloquial, a identidade de uma pessoa consistiria no conjunto de coisas que a definiria por meio de sua existência e assim o nome teria a função de representar esse conjunto de propriedades que definiriam a pessoa em todas as situações discursivas. A repetição do nome, portanto, corrobora a injunção imaginária de que há uma evolução linear de uma "personalidade" que distingue o sujeito.

Junto ao nome, um conjunto de propriedades, com descrições imaginárias de identificação, também é repetido, funcionando como um suporte descritivo significante. Esse suporte, re-atualizado a cada vez que o nome é evocado, apaga imaginariamente a discordância entre enunciado e enunciação. Dar um nome próprio não seria dizer em que ele é diferente, mas que ele é diferente. O nome próprio seria quase a forma vazia da diferença. Se às vezes pode vir a funcionar como predicado das descrições significantes, isso, contudo, não permite antever o sujeito.

Essas seriam algumas das injunções imaginárias em torno de um nome próprio: a estabilidade de uma referência a um ser estável, a inscrição na língua, na família e na sociedade pela escolha do nome, um nome correspondente a uma personalidade única, linearmente construída pela repetição do próprio nome.

Apesar disso, sabe-se que os sujeitos nem sempre compartilham essa harmonia imaginária prevista na teoria da referência. Um nome traz uma grande margem de indeterminação, a dimensão real. Traz também um símbolo com uma grande improbabilidade a priori e, por isso mesmo, evoca no sujeito a possibilidade de agregar vários significantes, a sua dimensão imaginária, por homofonia, na ordem da língua, e por homonímia, no sentido atribuído por Milner (1983), ${ }^{7}$ na ordem da alíngua. São significantes "acrescentados" ao nome.

Não se deve, contudo, esquecer que, para a linguiística e para a lógica, o que está em jogo é a distinção entre termos gerais (nomes comuns) e termos singulares (nomes próprios), distinção eminentemente ligada à teoria da referência. Por ter essa função determinativa de referência, os nomes próprios costumam ser compa- 
rados às descrições definidas ("mestre de Platão" para se referir a Sócrates, exemplo dado por Lacan no Seminário $I X)$ e aos indicadores dêiticos. De acordo com Peirce, os nomes próprios, os dêiticos (pronomes pessoais, demonstrativos, relativos) e as letras de um diagrama exercem a função de símbolos-índice:

ni comme qualité, ni comme <existence>, mais bien comme règle institué par l'acte de <baptême>" [...] Au sens où l'entend Peirce, cette existence actuelle qui s'oppose à une simple possibilité et à une necessité appartient bien en effet au référent du nome propre, cette existence actuelle fût-elle sur le mode imaginaire (PEIRCE, 1948 apud GRANGER, 1982, p. 33).

nem como qualidade, nem como existência, mas sim como regra instituída pelo ato de batismo (...) no sentido pelo qual se entende Peirce, esta existência atualizada que se opõe a uma simples possibilidade e a uma necessidade concernem com efeito ao referente do nome próprio, tal existência atualizada surgida sob a modalidade imaginária (PEIRCE, (1948) apud GRANGER, 1982, p. 33, tradução nossa).

Se o nome próprio tem função dêitica, isso pode querer dizer que o nome próprio não subentende a existência de um ser. Os pronomes pessoais, por exemplo, não dão existência ao "eu" nem ao "você" (na posição de segunda pessoa do enunciado), apenas marcam no plano da enunciação os lugares dos sujeitos, no sentido de apontar para alguém e não para a referência primária, no sentido de Lacan ([19--?], p. 3). A questão do julgamento de existência ou de inexistência do objeto costuma ser exemplificada pela proposição - Deus não existe -, dita por um ateu, que, ao nomear Deus, pressupõe sua existência, mesmo negando-a a seguir. Ou seja, o nome próprio não é garantia de existência sob o ponto de vista lógico.

Dizer que o nome próprio é um dêitico, como this, é dizer que ele aponta para um objeto a partir de um ponto de enunciação. A questão é saber quem está nesse lugar de enunciação, sabendo que os planos do enunciado e da enunciação não se correspondem para Lacan (1998). É da natureza do dêitico ser um "ponto geométrico" no enunciado:

O primeiro nome próprio para o Sr. Russell - eu já fiz alusão a meus seminários precedentes - é o "this", este aqui (this is the question). Eis o demonstrativo elevado ao nível de nome próprio. Não é menos paradoxal que o Sr. Russell encare friamente a possibilidade de chamar esse mesmo ponto John. [...] Russell nos diz que Sócrates não tem nenhum direito de ser considerado por nós como um nome próprio, sendo dado que desde muito tempo Sócrates não é mais um particular [...] a saber, que Sócrates era para nós o mestre de Platão, o homem que bebeu a cicuta etc. [...] É uma descrição resumida, isso nada mais é do que aquilo que ele chama de uma palavra 
para designar o particular em sua particularidade (LACAN, [19--?], p. 31).

Nessa possível função de índice, característica da dêixis, o significantenome próprio cumpriria seu papel na comunicação, como troca bem-sucedida de mal-entendidos, visto que para a psicanálise não são o signo e seus corolários, significado e referência, que a tornam possível. Para Lacan, Russell ignorou a questão principal presente na particularidade do nome próprio: "a relação mais radical do sujeito pensante com a letra" (LACAN, [19--?], p. 31). Contudo, em De uma questão preliminar a todo tratamento possível da psicose, Lacan, referindose a Peirce e a Jakobson, confere aos dêiticos (shifters, nome que emprega retirado de Jakobson) o lugar que "indica a posição do sujeito a partir da própria mensagem" (LACAN, 1998, p. 546). Mensagem de quem? Do Outro, cobrando a exigência do cumprimento de seu destino.

Se é que seja possível resumir as questões acima, eu diria que o que está em jogo nas abordagens epistemológicas que fazem a lingüística e a lógica, por um lado, e a psicanálise (Lacan), por outro, é onde recai o "ponto geométrico" atingido pelo nome próprio na enunciação. Enquanto o objeto-ser é o referente para lingüistas e lógicos, para a psicanálise, o referente é a letra. Sendo a letra, o nome próprio é destituído de sua condição de "sonoridade distintiva", como quer Gardiner, ou de sua condição de word for particular, como quer Russell, ou de "designador rígido", como quer Kripke. Mas, de uma forma ou de outra, essas maneiras de definir os nomes próprios encontram amparo imaginário na intuição dos sujeitos, ao se identificarem com a posição de objeto para a referência primeira de um Outro.

Além das injunções imaginárias ligadas à referência de um objeto, injunções simbólicas também estão presentes na nomeação performativa. Lévi-Strauss (apud GRANGER, 1982) chamou a atenção para uma outra função dos nomes próprios: a função de classificação. Os nomes teriam o papel de indicadores de classe e seriam atribuídos segundo a lógica de classes pré-ordenadas:

individus du groupe dans un référentiel totémique et parental plus ou moins complexe, fonction classificatoire dont une forme extrême serait donnée sans doute par l'usage des noms <ordinaux>, stéréotypés selon l'ordre de naissance des sept premières filles et des six premiers garçons, par exemple chez. les Dakotas. Il arrive même que le nom propre varie dans le temps selon la naissance et la mort des membres de la parenté (apud GRANGER, 1982, p. 28, grifos nossos).

a indivíduos de um grupo com um referencial totêmico e parental mais ou menos complexo, numa função classificatória pela qual uma forma extrema seria dada sem dúvida pelo uso dos nomes ordinários, estereotipados segundo a ordem de nascença das sete primeiras filhas e dos seis primeiros filhos, como por exemplo no grupo dos Dakotas. Acontece ainda que o nome próprio se modifique durante o tempo de acordo 
com o nascimento e a morte dos membros parentais (apud GRANGER, 1982, p. 28. Grifo nosso, tradução nossa).

A questão da morte, como impedimento da atribuição do nome do morto a um outro indivíduo, é significativa para a noção de "traço único" na relação da letra da escrita do nome com o significante sonoro. Nas terras dos Yurok ou dos Tiwi, não se pode pronunciar o nome do morto, assim como qualquer outro nome que mantenha relação de homofonia com o nome. É uma interdição da ordem da língua, pela homofonia (o significante sonoro ser tomado como outro), e pela ordem da cultura. Duas Leis estariam agindo ao mesmo tempo: a da língua e a da cultura.

Essas duas injunções simbólicas, a da língua e a da cultura, são responsáveis pela inscrição do sujeito na civilização. A função de identificação de classe pode ser atualizada no nome por meio de significantes marcadores de sexo, origem, classe social, época etc., inscrições simbólicas que fazem parte da marca da letra. Mesmo quando um nome próprio é assimilável a um nome comum como em "Jasmim", "Vida", "Vitória", ele se inscreve numa classe de um objeto identificável, mediante uma relação de homofonia, assimilando os significantes identificados aos termos gerais. A simbolização da classe, contudo, diz muito mais do desejo do Outro e do endereçamento que o sujeito faz quando cumpre o desejo do Outro do que da própria relação referencial posterior entre nome e objeto.

\section{O SIGNIFICANTE-NOME PRÓPRIO NA ESCRITA PSICÓTICA}

A marca simbólica da família, no caso dos sobrenomes - uma marca sobre a outra, um nome sobre outro - às vezes pode ser um elemento de confronto com o real em torno do nome:

[...] chego então a supor que alguma vez, talvez em gerações anteriores, teve lugar um fenômeno qualificável como assassinato de alma entre as famílias Flechsig e Schreber [...] Das duas famílias, entram em consideração vários nomes da família Flechsig em particular, além do prof. Paul Theodor Flechsig, também um certo Abraham Fürchtegott Flechsig e Daniel Fürchtegott Flechsig, esse último teria vivido no fim do século XVIII e se tornado "diabo auxiliar", por causa de um assassinato de alma. Em todo o caso, durante muito tempo estive em conexão nervosa com o prof. Paul Theodor Flechsig e com Daniel Fürchtegott Flechsig, (com o primeiro também na sua qualidade de alma?), e tive no corpo partes da alma de ambos (SCHREBER, 1903, p. 44).

Lacan comenta - o que ele chamou de "genealogia delirante" - a construção que Schreber faz com:

os nomes da linhagem real de Schreber - Gottfried, Gottlieb, Fürchtegott e sobretudo Daniel, que se transmite de pai para filho e do qual ele fornece o sentido em hebraico, para mostrar, 
na convergência de todos para o nome de Deus (Gott), uma cadeia simbólica importante, por manifestar a função do pai no delírio (LACAN, 1998, p. 586).

O que haveria de essencial no significante-próprio que o tornaria tão presente nas construções delirantes? Segundo Allouch (1995, p. 193), o nome próprio "presta-se à entrada em jogo da homofonia ${ }^{8}$ (no lugar da referência, à falta da referência)". Comentando o "estudo da homofonia schreberiana" de Lacan, presente no Seminário 3: as psicoses (1988), afirma que Schreber usa a "arma homofônica" para se defender do sentido que poderia levá-lo ao seu aniquilamento como sujeito. A dimensão da homofonia se dá "no plano de uma equivalência fonemática, significante, puramente significante" (ALLOUCH, 1995, p. 184). Haveria uma "coordenação fonemática" na ordem significante: "o que é importante não é a assonância, é a correspondência termo a termo de elementos de discriminação muito próximos" (ALLOUCH, 1995, p. 185).

Se a assonância está no imaginário, porque é da ordem do significante, e a homofonia no simbólico, porque é da ordem da escrita, segundo Allouch, isso marca de forma mais contundente a diferença radical entre significante e letra. Por exemplo, dois significantes que tenham a mesma seqüência de vogais, embora os sons restantes sejam diferentes, como em AMARELO e ANTERO, estariam unidos imaginariamente por assonância. R. tinha o significante AMARELO como uma espécie de centro na formação delirante de um "dicionário particular" (NOVAES, 1996). ANTERO, por sua vez, era o nome de seu pai, o qual, no "dicionário", aparecia como o seguinte verbete: $A N T E R O-A N T E R \hat{O}$, sendo $R \hat{O}$ a forma que seus outros irmãos chamavam R.

Em Schreber, contudo, é a homofonia que comanda a narração delirante. No caso dos nomes próprios em Memórias de um doente de nervos (SCHREBER, 1995), esses parecem ter dado a munição principal para a escrita do delírio (NOVAES, 2005, no prelo). Ao se tornarem "cifras" para o psicótico, os nomes próprios desencadeariam a busca por um significante "equivalente" para contornar o real. A homofonia é um acidente na linguagem e, às vezes, na língua, quando dois termos de raízes etimológicas distintas entram no sistema (como "manga", fruta, e "manga", parte de uma peça de roupa). É um acidente de linguagem, porque algo é escutado em lugar de outra coisa e essa escuta exigirá uma reescrita simbólica.

N. diz que, fora da oficina terapêutica, todos o chamavam de Índio por su cara aindiada - comenta com sorpresa el hecho que todos en el taller escuela lo lhaman N. (ALAZRAQUI; NASZEWSKI, 1999). Esse nome N. não produz assonância com "Índio", é necessária a escrita de um outro nome, já que o nome N. produz uma homofonia, ao escutar a seqüência sonora contida no nome como estranha. Falta a referência, falta o sentido, falta, enfim, qualquer coisa que pudesse fazer N. decifrar a "cifra".

As assonâncias e homofonias parecem ser intrínsecas à escrita psicótica, como formas de lidar com a letra do significante-nome próprio. Suas presenças seguem uma certa ordem estrutural e parecem depender do lugar que a função 
sujeito ocupa na relação com o Outro. C., por exemplo, vale-se tanto da assonância quanto da homofonia na escrita do significante-nome próprio:

P.: Que livro C.?

C.: Foi Brumas de Avalon que eu tava lendo.

P.: E você gostou? Hum?

C.: Eu não li o livro todo não eu li só foi só umas seis folhinhas do livro.

P.: E aí teve alguma coisa importante

C.: Aí eu tava vendo que o livro era quase maluco e a [...] do livro tinha 15 anos.

P.: Hum

C.: Escutava vozes igual a mim, mas "o nome dela era Ikaim" aí eu falei assim

P.: Como era o nome dela?

C.: "Ikaim" aí eu falei assim "ah então eu sou Ikaim desse livro" Era as Brumas de Avalon a deusa da magia aí tinha uma moça que era Morgana só o livro parece que a história era verdade mesmo tinha até uma parte que era "batida à máquina" e tudo aí eu falei então eu entrei dentro desse livro aí eles ficaram botando mais medo aí você entrou dentro desse livro agora você vai viver prá caramba você entrou dentro desse livro

P.: E qual é a explicação?

C.: Agora

P.: Hum. E qual é a explicação que você tem pra isso? você tem uma explicação por que isso acontece com você? Ou você acha alguma coisa?

C.: Não sei Não sei o livro era assim falando aquelas coisas assim "o livro era quase igualzinho a mim. ${ }^{10}$

Pode ser que para o psicótico "a é a" faça "sentido", por causa da homofonia. Para o psicótico parece que não se trata de "saber a que se refere 'a' ou se 'a' tem sentido". O problema é o enigma da letra e esse parece poder ser respondido por quaisquer outros significantes: "escutava vozes igual a mim, mas o nome dela era Ikaim aí eu falei assim [...] Ikaim aí eu falei assim ah então eu sou Ikaim desse livro". C., Ikaim e "assim" são significantes intercambiáveis nessa equação, já que são "interpretações das sonoridades". A verdade, inacessível, "era batida à máquina”, pura letra, o que parece esclarecer a afirmação de Lacan ([19--?], p. 35) de que "só pode haver definição do nome próprio à medida que nos apercebemos da relação da emissão nomeante com alguma coisa que em sua natureza radical é da ordem da letra". 
Mas qual seria a relação entre "emissão nomeante" e a escrita da letra? Sabe-se, desde as primeiras séries de escolarização, que os sons não correspondem às letras. A dificuldade na alfabetização é exatamente entender que uma letra pode corresponder a dois sons (como o "x" em tóxico), a nenhum som (como o "h"), um mesmo som pode corresponder a várias letras (o [s] com z, ç, s, ss, x, sc,), e até um som pode corresponder à letra nenhuma (como o [i] em advogado). Também se sabe que a primeira palavra que uma criança aprende a escrever é o seu nome (sua mão será guiada por uma mão outra) e que a letra inicial de seu nome terá uma função significante fundamental na entrada no mundo da escrita. É uma letra diferente das demais, é uma letra maiúscula. Durante algum tempo, aquela letra será sempre a representação dela (todo M é Mariana, por exemplo) e assim, sucessivamente, com as outras palavras que aprender-P é de Papai, M é de Mamãe etc.

Se o nome próprio é pura letra, a primeira letra do nome é sem dúvida um traço à parte, possivelmente até o traço único, de que fala Lacan [19--?]. Por razões inexplicáveis, certos pais "selecionam" certas letras como iniciais dos nomes de seus filhos. Às vezes, a mesma letra se repete entre os irmãos, o restante do nome parece ser uma mera adequação àquela exigência primeira. Essas letras podem ou não ser as mesmas dos nomes dos pais. Ela não pode ser maiúscula por acaso.

As sonoridades, por sua vez, são "interpretações significantes" da realidade perceptual da língua e são os sons que dão materialidade física à linguagem. Isso quer dizer que a sonoridade distintiva de um nome próprio já é uma "interpretação" significante do sujeito, no sentido psicanalítico do termo significante, assim como uma "interpretação" de um significante lingüístico num fluxo sonoro contínuo, por meio do caráter discreto que separa um significante do outro.

Já encontrava-se em Saussure [19--?], do Curso de Lingüística Geral, a idéia de que é o falante que faz o corte delimitador de um significante e de um significado num fluxo sonoro. Uma função sujeito, ${ }^{11}$ portanto, aparecia nas entrelinhas, mas não recebeu tratamento teórico na época (ficou latente na noção de "fala" como uso individual). Também já estava presente a noção de língua como um sistema de puras diferenças (nenhum valor positivo é atribuído a qualquer entidade lingüística; seu valor decorre da relação opositiva com as outras entidades). Assim, a noção de língua a qual estou me referindo não é a de que a língua é um sistema de signos, definição que é a mais reproduzida na lingüística e em outras áreas de saber, e sim que a língua oferece uma materialidade de entidades vazias e relacionais à espera de uma função sujeito que lhe dará o status significante no momento de demanda da fala. Em uma outra operação, esse significante irá se colar a um significado, dando origem ao signo. Quero dizer, o signo cumpre seu destino na fala a partir de uma função sujeito pela qual os cortes são efetuados nos dois eixos da linguagem - o sintagmático (metonímico) e o paradigmático (metafórico).

Essa leitura me é permitida pelos recentes manuscritos encontrados numa propriedade da família Saussure, cujo título previsto, possivelmente para um li- 
vro, seria De l'essence double du langage. Esses manuscritos estão publicados num livro intitulado Écrits de linguistique générale par Ferdinand de Saussure (BOUQUET; ENGLER, 2002). Destaquei dois pontos que me pareceram sensatos para avançar no entendimento do que poderia ser essa função sujeito em relação à letra, de que nos fala Lacan, e que, de uma certa forma, ratifica o que ele já propunha em O seminário sobre a "Carta Roubada” (LACAN, 1998, p. 13-66) e no já mencionado Seminário IX - A identificação, que a "figura vocal" 12 é passível de um acidente na ordem da transmissão e que as operações de corte e de atribuição de valor aos significantes e significados se dão em eixos separados por uma função sujeito.

Acidentes de transmissão, como assonâncias e homofonias, respeitados os limites que a materialidade da língua impõe. É uma materialidade psíquica que se caracteriza pela constância da repetição de suas identidades vazias e relacionais le propre du mot est de pouvoir désigner une chose, en tant que précisément elle manque (MILNER, 2002, p. 26) - adquirida na cultura por meio de inscrições simbólicas nessa materialidade, já que o infans faz sua entrada no "tesouro dos significantes" por meio da fala da mãe.

Significantes e significados, portanto, não existem sem o corte de uma função sujeito. Suas relações com as coisas referidas e suas relações entre si também dependem do ato discricionário de entidades, ato esse que eu estou aproximando da função sujeito:

Le signifié, ce n'est ni la chose ni le concept de la chose, c'est tout au plus ce qui permet de s'imaginer qu'on a nommé la chose. Autrement dit, le signifié ne représente rien, mais il permet de s'imaginer qu'il y a des représentations. Un familier de Freud ne devrait pas manquer d'évoquer la notion de Vorstellungsrepräsentanz, le <tenant-lieu de représentation>, selon la traduction que proposa un jour Lacan (MILNER, 2002, p. 30).

O significado não é a coisa nem o conceito da coisa, é tudo aquilo que permite se imaginar quando nomeamos a coisa.. Dito de outra forma, o significado não representa nada, apesar de permitir que se imagine que existem as representações. Alguém familiarizado com as idéias de Freud não deveria deixar de evocar a noção de Vorstellungsrepräsentanz,o lugartenente da representação, segundo a tradução proposta um dia por Lacan (MILNER, 2002, p.30, tradução nossa).

A figura vocal depende da função sujeito. De uma forma imprecisa, estou querendo aproximar o termo "figura vocal" do termo "sonoridade distintiva" normalmente atrelado ao nome próprio. É possível que o significante-nome próprio seja suscetível dessa mesma função. Ele tem de sofrer um corte num fluxo contínuo sonoro ou de ausência de sonoridade, um continuum de silêncio, para ser lançado fora do fluxo amorfo e cumprir seu destino significante. 
A letra, como uma escrita, na relação com o significante-nome próprio - a escrita da letra - só vai ter compromisso com o significante se essa letra for "interpretada" como um grafema. A letra inicial de um nome é um grafema porque indicia a latência de um significante. A letra numa equação matemática é um grafema distinto do grafema num nome próprio, porque os sistemas de "escritura" têm regras diferentes:

Um grafema é uma unidade gráfica mínima que entra na composição de um sistema de escritura; este elemento abstrato se realiza concretamente pelas formas chamadas alógrafas, cujo traço depende de outros elementos do sistema; o grafema corresponde então, na escrita alfabética, à letra, os alógrafos sendo as formas maiúsculas, minúsculas, cursivas etc. Ele pode corresponder a um fonema, a uma sílaba ou a um conceito segundo a escrita seja fonética, silábica ou ideográfica (DUBOIS, 2001, p. 227, tradução nossa).

A letra maiúscula do nome próprio, portanto, é um alógrafo, o que coloca esse termo sob suspeita já que, além de ser uma forma de escrita da letra, ele também pode ser entendido como um documento escrito por alguém em nome de outra pessoa (HOUAISS, 2001). A escrita é sempre de um Outro. As formas ou representações escritas dos grafemas são elementos abstratos que se encontram à disposição também de uma função sujeito que os torne significantes. Assim, juntamente com a sonoridade distintiva do nome, teríamos a escrita desse nome, o processo alográfico "na escrita do Outro".

Assim, nem a sonoridade de um nome e nem a letra corresponde ao significante-nome próprio. Para ilustrar essa não-correspondência, Lacan dá o exemplo das pinturas cuneiformes que conviviam na época com emissões vocais e nem por isso correspondiam a elas: são "manifestações de traços que não têm outro caráter que o de ser como esse traço de significantes e nada mais. Falamos de ideograma ou de ideografismo, o que dizer disso?" (LACAN, [19--?], p. 36).

Para que um traço, uma letra se torne um significante, é necessária a entrada de uma função "que é aquela do sujeito, não do sujeito no sentido psicológico, mas do sujeito no sentido estrutural" (LACAN, [19--?], p. 40). É possível que, por levar tudo ao pé da letra, o psicótico tenha uma relação tão apegada com a escrita. D., analfabeto, na época, morador de um hospital psiquiátrico na cidade de Niterói, me "contratou como sua secretária" para escrever suas cartas, durante o segundo semestre de 1992, período em que desenvolvi um trabalho na Oficina da Palavra no Hospital de Jurujuba. Na maioria das vezes, sem indicar destinatário, todas essas cartas terminavam com "representações associadas" (derivadas da ausência do significante-nome próprio) no lugar da "assinatura" e do "carimbo" de confirmação, também ditados a mim:

Fico feliz de continuar sendo o que não sou mas através desses lindos jardins você continua participando dessa linda flor. Por isso o meu coração se bateu mais forte. Eu sabendo que sou a 
sua rosa preferida no momento que você nesse lindo jardim. Assinado: o poeta que não existe. Carimbado: D.S.

$\mathrm{Na}$ tentativa de esquecer você não sei mais o que faço, pelo seu lindo olhar fico preso mais tempo me sinto bastante feliz pro seu lindo sorriso de amor. Sei que a paixão sempre foi uma loucura de amor olho para as estrelas não consigo ver o seu lindo brilho de amor a paz do seu sorriso de amor e a sua esperança de ser feliz pela paixão fico com a minha felicidade de amor com essa linda paixão de amor. Assinado: Perdido de amor. Carimbado: como faz falta um grande amor e uma grande paixão.

O nome D. nunca apareceu no campo "assinado", era sempre substituído por uma expressão substitutiva do nome, que estava lá "em ausência". D. possuía a "emissão vocal" desenfreada de significantes e é possível que a escrita, mesmo sendo feita por uma mão outra, era uma resposta ao real que se mostrava como enigma naquele nome. A forma do "carimbado" às vezes trazia o significantenome próprio, para logo em seguida se perder de novo.

Se a substituição do nome por uma expressão não-definida pode marcar uma forma da função sujeito lidar com o significante-nome próprio, às vezes esse mesmo significante pode surgir de uma forma excessiva e desmesurada para o sujeito. E. constrói um nome de divorciada (E.L.S. de S.S.) com o nome de solteira menos o último sobrenome (E.L.S.) mais aquele que ficou de fora na passagem para o nome de casada (S.), duplicando o S. retirado ao se casar. Com três nomes, um de solteira, um de casada e outro de divorciada, E. responde à ingerência do significante "bigamia", o qual ela não "admite" e que vem de Outro lugar. É a homofonia mais pura, na escuta de dois significantes no mesmo nome:

P.: Eu gostaria que a senhora me dissesse o seu nome completo

E.: E. L. S. T. de casada, mas sou divorciada E. L. S. de S. S., mas não tratei os meus documentos ainda porque não tive possibilidade de sair mas a Márcia me prometeu que vai cuidar de mim sobre isso ainda estou com o nome de casada mas não é bigamia porque eu não me casei ainda mas é erro e erro eu não admito. ${ }^{13}$

O., por outro lado, não reconhece o que é escutado homofonicamente em seu nome, um nome indevidamente inscrito por "lavagem cerebral". A solução psicótica é gerar significantes-substitutos que possam manter o funcionamento do sujeito na linguagem:

P.: como é o seu nome todo?

O.: meu nome é O.D.T. o meu nome de lavagem cerebral porque eu sofri quatro lavagens cerebrais.

P.: então conta pra mim como foram as lavagens. 
M.: é-é-é, meu nome verdadeiro é Nea eu vim de Estocolmo, Suécia, pro Rio de Janeiro a primeira lavagem cerebral foram as freiras que fizeram foram a freira Consuelo e uma outra.

$[\ldots]$

P.: mas voltando agora pro Canadá você me disse também que lá no Canadá você era campeã de ginástica masculina

O.: e eu lembrei encarnação anterior que meu nome era Ugli Canadê.

P.: como é o nome?

O.: Ugli Canadêt ${ }^{14}$

Ao se considerar essa outra função do nome próprio, a saber, a de escrita ou de que o "nome intervém naquilo que é afirmado" (ALLOUCH, 1995), a construção delirante vai se apoiar num suporte homofônico para ter os efeitos homonímicos necessários na escrita, efeitos imaginários, simbólicos e do real. Se a homofonia é metonímica, pois permite a substituição do significante-nome próprio, a homonímia é metafórica, sobrepondo os três registros num mesmo significante.

\section{ComentáRIOS FINAIS}

Re-escrevendo a definição inicial de nome próprio neste artigo, retomo a pergunta de Allouch (1995, p. 187) - "Que definição do nome próprio se vê convocada quando, na psicose, o significante é definido como seu equivalente?". O nome próprio é um significante funcionando como letra, como traço unário. A consequiência disso é retirá-lo da ordem da sonoridade e inscrevê-lo na ordem da escrita. Como suporte material do significante, a letra traz uma intimação de leitura, de uma decifração. O psicótico responde pela assonância e pela homofonia dos significantes.

"A letra, lê-se, como uma carta. Parece mesmo feita no prolongamento da palavra. Lê-se, e literalmente. Mas não é justamente a mesma coisa ler uma letra, ou bem ler" - afirma Lacan (1982, p. 39). A leitura de que se trata é a leitura dos significantes no sentido psicanalítico do termo, totalmente destituída de significações. Aos significados, no sentido lingüístico do termo, fica reservada a função de se tornarem efeitos na linguagem - "o significado não é aquilo que se ouve. O que se ouve é o significante. O significado é efeito do significante" (LACAN, 1982, p. 47).

É da natureza das cartas serem geradoras de mal-entendidos e decepções. Ler uma carta é sempre um ato de suspensão de sentidos, um estado totalmente diferente da leitura de um romance, por exemplo. Na homofonia de lettre - letra e carta (LACAN, 1998 - p. 13-66), que não se sustenta em português (talvez haja alguma assonância muito longínqua devido às vogais e consoantes presentes nas duas palavras), reforça-se a fórmula de Lacan de que o inconsciente é estruturado como uma linguagem. Essa linguagem, que responde à estrutura do inconsciente, tem de submeter sua lógica à outra lógica - a lógica da língua, uma língua que, 
concordando com Carlos Fuentes (2005, p. 3), "é a base da cultura, a porta da experiência, o teto da imaginação, o porão da memória, o quarto do amor e, acima de tudo, a janela aberta para o ar da dúvida, incerteza e questionamento".

E o que a lógica da escrita inconsciente retira da lógica do funcionamento da língua? Primeiramente, que o sistema fonético-fonológico responsável pelas sonoridades significantes não corresponde às regras da escrita. Em segundo lugar, que o que está em jogo não são os significantes em si, mas a cadeia e seus movimentos internos nos dois eixos: metonímico e metafórico. Para passar da escrita da letra para o significante-nome próprio, nas psicoses, os movimentos da assonância e da homofonia (a serviço do Imaginário e do Simbólico) ocorrem no campo das sonoridades, já que o campo da escrita da letra é o campo do real. O que permite que um mesmo nome se enlace nos três nós é a possibilidade homonímica de um nome sempre poder ser outro:

l'homonymie des noms est constante, qu'ils se profèrent en I, en R ou en S. Elle n'est que le témoignage de leur non-rapport absolu, or, de ce que tels existants soient sans rapports, suit précisément qu'ils peuvent coïncider (MILNER, 1983, p. 53).

a homonímia dos nomes é constante, sejam eles proferidos em I (imaginário), em R (real) ou em S (simbólico). Ela não é senão a testemunha dos fracassos absolutos de relação entre eles, ou de que eles existam sem relação derive precisamente que eles podem coincidir (MILNER, 1983, p. 53, tradução nossa).

\section{Notas}

1 O termo "injunção" será usado neste artigo no sentido de imposição coercitiva de uma lei (uma das acepções do termo, cf. Houaiss, Dicionário Eletrônico, 1.0, 2001). A consideração de injunções imaginárias como crenças e ilusões de verdades que costuram o laço social; injunções simbólicas, como significantes impostos pelo desejo do Outro, interpretando esse Outro como toda forma de Lei, seja ela da língua, da cultura ou do desejo e as injunções do Real como "exigências" e "pressão" de algo à espreita de uma "solução" significante para o sujeito decorrem do conceito de "homonímia" proposto por Milner (1983). Outros esclarecimentos encontram-se na nota 7.

2 O termo usado na tradução para o português de Portugal é "nominação performativa", mas prefiro usar o termo nomeação por ser mais usual no Brasil e por não interferir na designação do fenômeno performativo.

3 Falando sobre o "ato oficial dos pais" de dar nomes aos bebês, Levit e Dubner (2005) apresentam um resultado de uma pesquisa realizada na Califórnia com os 20 nomes "mais brancos" e os 20 nomes "mais negros" para meninos e meninas e de como esses nomes íam sendo subtituídos por outros à medida que um "nome branco" começasse a fazer parte da lista dos "nomes negros", revelando a correlação entre o nome de um bebê e o status socioeconômico dos pais. Essa é com certeza uma forma de "conveniência semântica" que não se restringe à Califórnia.

4 O termo "interpelação" foi tirado do termo "interpelação virtual” sugerido por Granger (1982) para se referir à condição fundamental de funcionamento dos nomes próprios em situações de enunciação, em que um sujeito é convocado a ocupar uma função de segunda pessoa, para quem se fala.

5 Refiro-me às abordagens de Pariente (1973), Gary-Prieur (1994), Molino (1982) e Gardiner (apud LACAN, [19--?]).

6 Faço referência a Frege (1978), Kripke (1982) e Russell (apud AUDI, 1995).

7 No sentido, atribuído por Milner (1983), de que a homofonia (da ordem da língua) pode se esvanecer na escritura, mas a homonímia (da ordem da lalangue), não. O termo lalangue, da ordem do singular, do inconsciente, foi proposto por Lacan (1982) para marcar a distinção com langue, 
que faz série e imaginariamente aglutina um grupo social em torno de suas regras gramaticais e promessas de sentidos de seu léxico. A lalangue acaba sendo determinante do equívoco, já que, em seu instante de nomeação, ela conclama em si os três registros necessários à economia do sujeito: o imaginário, o simbólico e o real.

8 Toda vez que se têm dois significantes simultâneos numa mesma escuta, com a mesma sonoridade, estamos diante da homofonia. Sonnenstein, nome do asilo em que Schreber estava internado durante a escrita das Memórias, pode ter sido uma "invasão homofônica" e se transformado em outro significante (ver NOVAES, 2005).

9 Exemplo extraído do texto de Alazraqui, H. e Naszewski, M. Algunas puntualizaciones sobre el dispositivo hospital de día, coordenadores do serviço de saúde mental do Hospital Eva Péron em Buenos Aires.

${ }^{10}$ Fragmento de entrevista realizada no Instituto de Psiquiatria da UFRJ, material cedido ao banco de dados das pesquisas que a autora do presente artigo realiza desde 1991.

${ }^{11}$ Saussure não usa o termo "função sujeito" e sim sujeito falante, que parece remeter a um sujeito psicológico. Diz que as entidades lingüísticas são psíquicas, mas também não se sabe qual a natureza desse psiquismo. De qualquer maneira, estou me sentindo livre para propor uma leitura em que há uma função, reconhecida por Lacan e por Saussure, colocada no circuito < fala $<$ significante $<$ significado e <letra.

${ }^{12}$ O termo "figura vocal" e/ou "signo" aparece no lugar do termo "significante" encontrado no Curso: On appelle forme une "figure vocale" qui est déterminée pour "la conscience des sujets parlants". La seconde mention est en réalité superflue, parce qu'il n'existe rien que ce qui existe pour la conscience; donc si une figure vocale est déterminée, c'est qu'elle l'est immédiatement [...] une figure vocal devient une forme depuis l'instant crucial où on l'introduit dans le jeu de signes appelé langue (BOUQUET ; ENGLER, 2002, p. 37-8).

13 idem à nota 10.

14 idem à nota 10 .

\section{REFERÊNCIAS}

ALAZRAQUI, H.; NASZEWSKI, M. Algunas puntualizaciones sobre el dispositivo hospital de dia. [Buenos Aires]: [s.n.], 1999.

ALLOUCH, J. Letra a letra: transcrever, traduzir, transliterar. Rio de Janeiro: Companhia de Freud, 1995.

AUDI, R. The Cambridge Dictionary of Philosophy. Cambridge: University Press, 1995.

AUSTIN, J. L. How to do things with words. Oxford: University Press, 1962.

BOUQUET, S.; ENGLER, R. Écrits de linguistique générale par Ferdinand de Saussure. Paris: Gallimard, 2002.

DUBOIS, J. et al. Dictionnaire de linguistique. Paris: Larousse, 2001.

FREGE, G. Lógica e Filosofia da Linguagem. São Paulo: Cultrix, 1978.

FUENTES, C. O elogio da incerteza. Folha de São Paulo, São Paulo, 9 out. 2005, Caderno Mais, p. 3.

GARY-PRYEUR, M. N. Grammaire du nom propre. Paris: Presses Universitaires de France, 1994.

GRANGER, G. A quoi servent les noms propres. Langage, [S.1.] n. 66, p. 21-36, 1982. 
HOUAISS, A. Dicionário Eletrônico Houaiss de Língua Portuguesa, versão 1.0. Rio de Janeiro: Instituto Antonio Houaiss, 2001.

KRIPKE, S. La logique des noms propres: naming and necessity. Paris: Minuit, 1982.

LACAN, J. Escritos. Rio de Janeiro: J. Zahar, 1998.

. O Seminário: as psicoses. Tradução Aluísio Menezes. Rio de Janeiro: J. Zahar, 1988. Livro 3.

. O Seminário: mais, ainda. Rio de Janeiro: J. Zahar, 1982. Livro 20.

. Seminário IX: a identificação (1961). [S.1.]: Escola Brasileira de Psicanálise Movimento Freudiano, [19--?]. Inédito, mimeografado.

LEVIT, S.; DUBNER, S. Freakonomics: o lado oculto e inesperado de tudo que nos afeta. Rio de Janeiro: Elsevier, 2005.

LYONS, J. Semântica I. Lisboa: Presença; São Paulo: Martins Fontes, 1977.

MILNER, J.-C. Le périple structural: figures et paradigme. Paris: Seuil, 2002. . Les noms indistincts. Paris: Seuil, 1983.

MOLINO, J. Le nom propre dans la langue. Langage, [S.1.], n. 66, p. 5-20, 1982.

NOVAES, M. Os dizeres nas esquizofrenias: uma cartola sem fundo. São Paulo: Escuta, 1996.

. A função anagramática dos nomes próprios nas psicoses. Gragoatá, Niterói, 2005. No prelo.

PARIENTE, J.- C. Le langage et l'individuel. Paris: Armand Colin, 1973.

SAUSSURE, F. Curso de Lingüística Geral. São Paulo: Cultrix, [19--?].

SCHREBER, D. P. Memórias de um doente dos nervos [1903]. Tradução de Marilene Carone. São Paulo: Paz e Terra, 1995.

Recebido em: março/2005

Aceito em: janeiro/2006 